\title{
KRATAK PREGLED MODELA OTICAJA I EROZIJE ZASNOVANIH NA FIZIČKIM PROCESIMA
}

\author{
Ognjen Gabrić ${ }^{1}$ \\ Mirjana Horvat ${ }^{2}$ \\ Zoltan Horvat ${ }^{3}$
}

UDK: 551.311.21:001.891.54

\section{DOI: 10.14415/zbornikGFS27.16}

Rezime: Izučavanje procesa oticaja i erozije predstavlja jedan od osnovnih istraživanja u hidrologiji. Na bazi terenskih $i$ laboratorijskih merenja, a uporedo sa razvojem računarske tehnike, razvijeni su $i$ modeli oticaja $i$ erozije zasnovani na rešavanju jednačina kojima se opisuje fizika procesa. U radu je prikazan opšti opis i uporedni prikaz nekoliko modela oticaja i erozije zasnovanih na jednačinama koji opisuju celokupnu dinamiku nastanka i transporta nanosa na slivu.

Ključne reči: erozija, model, oticaj

\section{UVOD}

Razvoj modela za proračun oticaja i erozije započeo je sredinom prve polovine XX veka, kada je Zingg objavio empirijsku formulu pomoću koje je erozija sračunata na osnovu dužine i nagiba tla [1].

Najviše upotrebljavan model za proračun erozije predstavlja USLE koji je razvijen od strane USDA pod vođstvom Wischmeier-a i Smith-a. Model je prvi put objavljen 1965. godine u Agriculture Handbook 282 [2] dok je nešto prerađena verzija objavljena 1978. godine u Agriculture Handbook 537. Zbog nedostataka koje je imao mnogi istraživači su predstavljali poboljšane modele USLE-a. Jedna od značajnijih modifikacija bio je model MUSLE (Modified Universal Soil Loss Equation) [3] a zatim, 1987. godine, i model RUSLE (Revised Universal Soil Loss Equation). Osim navedenih modela, u svetu je razvijeno još mnoštvo empirijskih modela zasnovanih na empirijskim vezama pojedinih činilaca procesa oticaja i erozije [4], [5].

$\mathrm{Na}$ bazi terenskih i laboratorijskih merenja, a uporedo sa razvojem računarske tehnike, razvijani su i matematički modeli oticaja i erozije. Pod matematičkim modeliranjem erozionih i transportnih procesa podrazumeva se opisivanje ovih procesa jednačinama $i$ njihovo povezivanje u integrisane modele koji opisuju celokupnu dinamiku geneze i transporta nanosa u slivu [6]. Modeli predstavljaju korisno sredstvo, čijom primenom je

\footnotetext{
${ }^{1}$ dr Ognjen Gabrić, diplomirani građevinski inženjer, Građevinski fakultet Subotica, Kozaračka 2a, 24000 Subotica, Srbija, e-mail: ogabric@gf.uns.ac.rs

2 dr Mirjana Horvat, diplomirani građevinski inženjer, Građevinski fakultet Subotica, Kozaračka 2a, 24000 Subotica, Srbija, e-mail: isicm@gf.uns.ac.rs

${ }^{3}$ dr Zoltan Horvat, diplomirani građevinski inženjer, Građevinski fakultet Subotica, Kozaračka 2a, 24000 Subotica, Srbija, e-mail: horvatz@gf.uns.ac.rs
} 
moguće predvideti kako će se procesi oticaja i erozije odvijati i kako će se promena neke karakteristike sliva odraziti na promenu ovih veličina. U fizički baziranim modelima procesi erozije zemljišta i transporta nanosa na slivu opisuju se kao odgovor sliva na određene klimatske, topografske, pedološke, geološke i vegetacione uslove na slivu [7]. U nastavku rada dat je opšti opis i uporedni prikaz karakteristika šest fizički baziranih modela oticaja i erozije: ANSWERS-2000, CREAMS, WEPP, KINEROS2, EUROSEM i SHETRAN.

Cilj rada je upoznavanje korisnika modela sa načinom modeliranja procesa formiranja površinskog oticaja, transportnog kapaciteta i erozije sa sliva. Modeli su upoređivani sa aspekta modeliranja sledećih elemenata procesa: površinskog oticaja, erozije kišom, erozije površinskim tečenjem i modeliranjem transportnog kapaciteta.

\section{OPIS MODELA}

\subsection{KINEROS2}

KINEROS2 (The KINEmatic Runoff EROSion Model) je distributivan, fizički zasnovan model koji opisuje procese intercepcije, infiltracije, površinskog oticaja i erozije sa sliva pod dominantnim uticajem površinskog toka [8]. Koncepcija modela se zasniva na podeli sliva na kaskadno poređane nizove površina i kanala preko kojih se oticaj propagira nizvodno koristeći metodu konačnih razlika za rešavanje 1-D jednačina kinematskog talasa.

U modelu, infiltracija se može modelisati za najviše dva sloja zemljišta konačnih debljina. Javlja se usled padavina ili od površinskog zadržavanja vode u depresijama a modeliše se primenom Smith-Parlang-ovog modela.

Oticaj se modeliše kao 1-D proces jednačinama kinematskog talasa:

$$
\begin{aligned}
& \frac{\partial h}{\partial t}+\frac{\partial Q}{\partial x}=q(x, t) \\
& Q=\alpha h^{m}
\end{aligned}
$$

gde je $h$ dubina vode u preseku, $t$ vreme, $Q$ protok, $q$ lateralni dotok, $x$ rastojanje duž toka, a $\alpha$ i $m$ parametri koji zavise od načina obračuna trenja. Za otpore trenja računatim po Manning-ovoj formuli:

$$
\alpha=\frac{S^{1 / 2}}{n} ; m=\frac{5}{3}
$$

a za otpore trenja računate po Chezy-jevoj formuli:

$$
\alpha=C S^{1 / 2} ; m=\frac{3}{2}
$$

gde je $S$ nagib dna, $n$ Manning-ov koeficijent hrapavosti a $C$ Chezy-jev koeficijent. 
KINEROS2 zasebno računa eroziju usled erozionog dejstva kiše i eroziju usled tečenja vode - hidraulička erozija. Erozija se računa kako za slivne površine tako i za kanale.

Jednačina koja opisuje kretanje sedimenata je jednačina kontinuiteta koja je slična kinematskoj jednačini tečenja vode:

$$
\frac{\partial\left(A C_{s}\right)}{\partial t}+\frac{\partial\left(Q C_{s}\right)}{\partial x}-e(x, t)=q_{s}(x, t)
$$

gde je $C_{s}$ koncentracija sedimenata, $Q$ protok, $A$ površina poprečnog preseka, $e$ intenzitet erozije i $q_{s}$ intenzitet lateralnog dotoka sedimenata u kanale.

Za površinske elemente, pretpostavka je da se $e$ sastoji iz dve osnovne komponente produkcije erodovanog zemljišta usled kiše, $e_{s}$ i hidrauličke erozije (ili taloženja), $e_{h}$, kao odnosa tangencijalnih sila i gravitacije. $\mathrm{S}$ toga, e može biti pozitivno (povećanje koncentracije nanosa u vodi) ili negativno (taloženje). Ukupna erozija predstavlja sumu erozije erozionim dejstvom kiše i hidrauličke erozije:

$$
e=e_{s}+e_{h}
$$

$\mathrm{Na}$ osnovu malog broja eksperimentalnih istraživanja, erozija kišom se može prikazati kao:

$$
\begin{array}{ll}
e_{s}=c_{f} k(h) r^{2} & ; q>0 \\
e_{s}=0 & ; q<0
\end{array}
$$

gde je $c_{f}=422 * \mathrm{~K}_{\mathrm{USLE}}\left(\Phi_{\mathrm{f}}\right)$ konstanta vezana za zemljište i osobine površine, $K_{U S L E}$ vrednost faktora K iz USLE modela, $\Phi_{f}$ faktor ublaženja erozije biljnim pokrivačem, $k(h)=\exp \left(-c_{h} h\right)$ redukcioni faktor erozije kišom usled povećavanja dubine vode.

Za hidrauličku eroziju, KINEROS2 polazi od pretpostavke da za određene uslove tečenja vode postoji koncentracija nanosa koja može biti transportovana ukoliko se ti uslovi nastave - transportni kapacitet. Hidraulička erozija, $e_{h}$ je linearno proporcionalna razlici između transportnog kapaciteta i trenutne koncentracije nanosa.

$$
e_{h}=c_{g}\left(C_{m}-C_{s}\right) A
$$

gde je $C_{m}$ transportni kapacitet, $C_{s}(x, t)$ trenutna lokalna koncentracija nanosa a $c_{g}$ koeficijent intenziteta pronosa predstavljen kao količnik brzina tonjenja čestice $v_{f}$ i dubine vode $h$.

$$
\begin{aligned}
& c_{g}=\frac{v_{f}}{h} \\
& v_{f}^{2}=\frac{4 g\left(\rho_{s}-1\right)}{3 C_{D}} d
\end{aligned}
$$




$$
\begin{aligned}
& C_{D}=\frac{24}{R_{n}}+\frac{3}{\sqrt{R_{n}}}+0.34 \\
& R_{n}=\frac{v_{f} d}{v}
\end{aligned}
$$

gde je $g$ gravitaciono ubrzanje, $\rho_{s}$ bezdimenzionalna gustina zrna, $d$ prečnik zrna, $R_{n}$ Reynolds-ov broj, $C_{D}$ koeficijent sile otpora.

Za proračun transportnog kapaciteta koristi se modifikovana jednačina Govers-a:

$$
C_{m}=\frac{0.05}{d\left(\gamma_{s}-1\right)^{2}} \sqrt{\frac{S h}{g}}\left(\Omega-\Omega_{c}\right)
$$

gde je $d$ prečnik zrna nanosa, $\gamma_{s}$ specifična težina čestica u suspenziji, $S$ nagib linije nivoa, $h$ dubina vode, $\Omega$ jedinična snaga toka (proizvod brzine i nagiba linije nivoa), $u$ brzina vode, $\Omega_{c}$ granična jedinična snaga toka za male dubine tečenja $(0.004)$.

\subsection{WEPP}

WEPP (Water Erosion Prediction Project) je model kontinualnih kišnih epizoda za procenu erozije sa poljoprivrednih površina, površina pod šumom, građevinskih parcela i urbanih površina [9]. Preporučena veličina slivne površine je do 250 ha.

Za proračun evapotranspiracije model koristi Ričijevu metodu a za proračun infiltracije metodu Green-Ampt Mein Larson.

Proračun površinskog oticaja se vrši rešavanjem jednačina kinematskog talasa (izrazi $1 \mathrm{i}$ 2). Obračun trenja vrši se Chezy-jevim izrazom (izraz 4) [10].

Proračun kretanja i transporta sedimenata sa sliva vrši se jednačinom kontinuiteta za ustaljeno kretanje nanosa:

$$
\frac{d G}{d x}=D_{f}+D_{i}
$$

gde je $G$ koncentracija nanosa, $D_{f}$ erozija u brazdama a $D_{i}$ površinska erozija.

Proračun površinske erozija ima konceptualni karakter. Smatra se da je proporcionalna proizvodu intenziteta kiše $R$, površinskog oticaja $Q$ i parametra erodibilnosti zemljišta $K_{r}$.

$$
D_{i}=R Q K_{r}
$$

Erozija u brazdama se javlja kada je tangencijalni napon na kontaktu vode i zemljišta veći od kritičnog napona i kada je koncentracija sedimenata u toku manja od transportnog kapaciteta toka. Za slučaj pokretanja nanosa:

$$
D_{f}=D_{c}\left(1-\frac{G}{T_{c}}\right)
$$

174 | JOURNAL OF FACULTY OF CIVIL ENGINEERING 27 (2015) | 
gde je $D_{c}$ erozioni kapacitet toka a $T_{c}$ transportni kapacitet toka. Erozioni kapacitet se računa preko izraza:

$$
D_{c}=K_{r}\left(\tau_{f}-\tau_{c}\right)
$$

gde je $\tau_{f}$ tangencijalni napon toka $\mathrm{u}$ brazdi i $\tau_{\mathrm{c}}$ kritičan tangencijalni napon.

$$
\tau_{f}=\gamma \bar{S} R\left(\frac{\tau}{\tau_{a}}\right)
$$

gde je $\gamma$ specifična težina vode, $\bar{S}$ prosečan nagib brazde, $R$ hidraulički radijus, $\tau$ stvarni tangencijalni napon, $\tau_{a}$ prosečan tangencijalni napon.

Kritičan tangencijalni napon $\tau_{c}$ je u funkciji Reynoldsovog broja i određuje se uz pomoć Shields-ovog dijagrama [11].

Ukoliko je koncentracija sedimenata u toku veća od transportnog kapaciteta, dolazi do deponovanja i tada je:

$$
D_{f}=\frac{\beta V_{f}}{q}\left(T_{c}-G\right)
$$

gde je $\beta$ koeficijent turbulencije usled kišnih kapi, $V_{f}$ brzina tonjenja zrna nanosa i $q$ jedinični oticaj.

U modelu WEPP, transportni kapacitet je funkcija rastojanja i računa se pomoću izraza:

$$
T_{c}=k_{t} \tau_{f}^{3 / 2}
$$

gde je $\mathrm{k}_{\mathrm{t}}$ transportni koeficijent.

\subsection{SHETRAN}

SHETRAN predstavlja programski paket zasnovan na interakciji nekoliko različitih modula kojima su opisani procesi evapotranspiracije i intercepcije, kretanje vode po površini terena i kroz hidrografsku mrežu, kretanje kroz nezasićenu i zasićenu sredinu i modula u kome su opisani erozioni i transportni procesi.

Model infiltracije u nezasićenoj zoni zasnovan je na rešavanju jednodimenzionalne Richards-ove diferencijalne jednačine a u zasićenoj zoni rešavanjem dvodimenzionalne jednačine Boussinesq-a [12]. Evapotranspiracija se određuje preko Penman-Monteith metode.

Tečenje po površini terena simulira se rešavanjem diferencijalnih jednačina difuzionog talasa u x i y pravcu. Dinamička jednačina, u oba pravca, može da se napiše u sledećem obliku [13]: 


$$
S_{f x}+\frac{\partial\left(z_{g}+h_{0}\right)}{\partial x}=0 ; S_{f y}+\frac{\partial\left(z_{g}+h_{0}\right)}{\partial y}=0
$$

gde je $S_{f}$ nagib trenja, $z_{g}$ kota dna a $h_{0}$ dubina vode. Ukoliko se obračun trenja izvrši po Manning-ovoj formuli:

$$
S_{f x}=\frac{u_{x}^{2}}{K_{x}^{2} h_{0}^{4 / 3}} ; S_{f y}=\frac{u_{y}^{2}}{K_{y}^{2} h_{0}^{4 / 3}}
$$

i kombinovanjem izraza (15) i (16) dobija se jednačina difuzionog talasa u x i y pravcu:

$$
\begin{aligned}
& Q_{x}=u_{x} h_{0} w_{x}-K_{x}\left[-\frac{\partial\left(z_{x}+h_{0}\right)}{\partial x}\right]^{1 / 2} w_{x} h_{0}^{5 / 3}-\frac{K_{x} w_{x} h_{0}^{5 / 3}}{L_{x}^{1 / 2}}\left[z_{u}-z_{d}\right]^{1 / 2} \\
& Q_{y}=u_{y} h_{0} w_{y}-K_{y}\left[-\frac{\partial\left(z_{y}+h_{0}\right)}{\partial y}\right]^{1 / 2} w_{y} h_{0}^{5 / 3}-\frac{K_{y} w_{y} h_{0}^{5 / 3}}{L_{y}^{1 / 2}}\left[z_{u}-z_{d}\right]^{1 / 2}
\end{aligned}
$$

gde je $w$ širina elementa u pravcu tečenja, $K$ Strickler-ov koeficijent (inverzna vrednost Manning-ovog koeficijenta hrapavosti), $L$ rastojanje između centara dvaju elemenata, $z_{u}$ i $z_{d}$ kote nivoa vode uzvodno i nizvodno a $Q$ proticaj.

Transport nanosa $u$ pravcu tečenja vode računa se preko dvodimenzionalne jednačine kontinuiteta za neustaljeno tečenje:

$$
\frac{\partial\left(c_{i} h\right)}{\partial t}+(1-\lambda) \frac{\partial z_{i}}{\partial t}+\frac{\partial g_{x i}}{\partial x}+\frac{\partial g_{y i}}{\partial y}=0
$$

gde je $h$ dubina vode, $c_{i}$ koncentracija i-te frakcije sedimenta, $\lambda$ gornjeg sloja, $z$ debljina gornjeg sloja, $g$ volumetrijski transport nanosa.

Model obračunava eroziju usled kišnih kapi i kapi koje padaju sa lišća empirijskim obrascem [14]:

$$
D_{r}=k_{r} F_{w}\left(1-C_{g}-C_{r}\right)\left(M_{r}+M_{d}\right)
$$

gde je $D_{r}$ intenzitet erozije kišnim kapima i kapima sa lišća, $k_{r}$ erodibilnost zemljišta kišnim kapima, $C_{g}$ i $C_{r}$ procentualno učešće zaklonjenog zemljišta, $M_{r}$ i $M_{d}$ energija udara kišne kapi odnosno kapi koja padne sa lista. Zaštitni efekat površinskog sloja vode na eroziju, $F_{w}$, se obračunava preko sledećeg izraza:

$$
F_{w}= \begin{cases}1 & h \leq d_{m} \\ \exp \left(1-\frac{h}{d_{m}}\right) & h>d_{m}\end{cases}
$$

gde je $h$ dubina vode a $d_{m}$ efektivni prečnik kapi.

Energija udara kišnih kapi na površinu sliva, $M_{r}$, određuje se empirijskim izrazom: 


$$
M_{r}=\left(1-C_{c}\right) a_{1} I^{b_{1}}
$$

gde je $C_{c}$ procenat zemljišta zaštićen vegetacijom, $I$ intenzitet kiše a koeficijenti $a_{l}$ i $b_{l}$ dati su tabelarno u funkciji intenziteta kiše.

Tabela 1. Vrednosti koeficijenata $a_{1} i{ }_{1}$
\begin{tabular}{|c|c|c|}
\hline $\mathrm{I}(\mathrm{mm} / \mathrm{h})$ & $\mathrm{a}_{1}$ & $\mathrm{~b}_{1}$ \\
\hline $0-10$ & $2.6893 \cdot 10^{-8}$ & 1.6896 \\
\hline $10-50$ & $3.7514 \cdot 10^{-8}$ & 1.5545 \\
\hline $50-100$ & $6.1192 \cdot 10^{-8}$ & 1.4242 \\
\hline$\geq 100$ & $11.737 \cdot 10^{-8}$ & 1.2821 \\
\hline
\end{tabular}

Energija udara kapi sa lišća se takođe obračunava empirijskim izrazom:

$$
M_{d}=\frac{\pi}{6} V_{d}^{2} \rho^{2} d_{1}^{3} L_{d} D R A I N A
$$

gde je $V_{d}$ brzina kapi koja pada sa lišća, $\rho$ gustina vode, $d_{l}$ prečnik kapi koja pada sa lista, $L_{d}$ procenat količine vode koja se sliva se lišća i DRAINA intenzitet dotoka sa pokrivača.

$$
V_{d}=\sqrt{\frac{M}{\beta} g\left(1-e^{-\frac{2 X \beta}{M}}\right)}
$$

gde je $M$ prosečna masa kapi sa lišća, $\beta$ koeficijent trenja a $X$ visina padanja. Odnos $M / \beta$ se određuje iz relacije:

$$
\frac{M}{\beta}=a_{2}+b_{2} d_{1}
$$

Tabela 2. Vrednosti koeficijenata a 2 i b2

\begin{tabular}{|c|c|c|c|}
\hline $\mathrm{d}_{1}(\mathrm{~m})$ & $\mathrm{X}(\mathrm{m})$ & $\mathrm{a}_{2}$ & $\mathrm{~b}_{2}$ \\
\hline$<0.0033$ & sve dužine & 0 & 2200 \\
\hline$\geq 0.0033$ & $<7.5$ & 1.93 & 1640 \\
\hline$\geq 0.0033$ & $\geq 7.5$ & 5.14 & 660 \\
\hline
\end{tabular}

Površinska erozija usled tečenja vode po površini sliva, $D_{q}$, se obračunava preko sledećeg pristupa:

$$
D_{q}= \begin{cases}k_{f}\left(1-C_{p}\right)\left[\frac{\tau}{\tau_{e c}}-1\right] & \tau>\tau_{e c} \\ 0 & \tau \leq \tau_{e c}\end{cases}
$$


gde je $k_{f}$ koeficijent erodibilnosti površinskog tečenja, $\tau$ tangencijalni napon površinskog tečenja, $\tau_{e c}$ kritični tangencijalni napon.

Tangencijalni napon površinskog toka obračunava se iz relacije:

$$
\tau=\rho g h S
$$

a kritičan napon:

$$
\begin{array}{r}
\tau_{e c}=\left(\rho_{s}-\rho\right) g D_{50} a_{3} R_{*}^{b 3} \\
R_{*}=\max \left[0.03, \frac{D_{50}(\tau / \rho)^{0.5}}{v}\right]
\end{array}
$$

gde je $\rho_{s}$ gustina sedimenta, $\rho$ gustina vode, $g$ gravitaciono ubrzanje, $D_{50}$ prosečan prečnik zrna nanosa a $R *$ Reynoldsov broj. Vrednost parametara $a_{3}$ i $b_{3}$ data je u tabeli 3 .

Tabela 3. Vrednosti koeficijenata a 3 i b3

\begin{tabular}{|c|c|c|}
\hline $\mathrm{R}_{*}$ & $\mathrm{a}_{3}$ & $\mathrm{~b}_{3}$ \\
\hline $0.03-1$ & 0.1 & -0.3 \\
\hline $1-6$ & 0.1 & -0.62 \\
\hline $6-30$ & 0.033 & 0 \\
\hline $30-135$ & 0.013 & 0.28 \\
\hline $135-400$ & 0.03 & 0.1 \\
\hline$>400$ & 0.056 & 0 \\
\hline
\end{tabular}

Transportni kapacitet površinskog toka se obračunava odabirom jednog od dva ponuđena metoda, pomoću formule Yalin-a:

$$
G_{t o t}=0.635 \sqrt{\frac{\tau}{\rho}} l D_{50} \delta\left[1-\frac{1}{a \delta} \ln (1+a \delta)\right]
$$

ili pomoću jednačine Engelund-Hansen-a:

$$
G_{t o t}= \begin{cases}\frac{0.05 Q^{2} S^{\frac{3}{2}}}{\sqrt{g h}\left(\frac{\rho_{s}}{\rho}-1\right)^{2} D_{50} l} & h>0 \\ 0 & h \leq 0\end{cases}
$$

gde je $l$ širina toka a vrednosti $a$ i $\delta$ se računaju preko izraza:

$$
\delta=\max \left[0, \frac{\tau}{\tau_{e c}}-1\right]
$$




$$
a=2.45 \sqrt{\frac{\tau_{e c}}{\left[\left(\rho_{s}-\rho\right) g D_{50}\right]}}\left(\frac{\rho_{s}}{\rho}\right)^{-0.4}
$$

Gore navedene jednačine za proračun transportnog kapaciteta su razvijene za proračun transporta nanosa u kanalima i njihova upotreba za proračun površinske erozije nije $u$ potpunosti ispitana. U programskom paketu je ostavljena mogućnost korisniku da samostalno odredi maksimalnu koncentraciju sedimenata.

\subsection{ANSWERS-2000}

ANSWERS-2000 (Areal Nonpoint Source Watershed Response Simulation) predstavlja fizički baziran model dugoročnih, kontinualnih simulacija za procenu uticaja efekata mera na zaštitu od erozije i nutrijenata sa poljoprivrednih zemljišta veličine do 2000 ha [15]. Model je baziran na konceptu da u svakoj tački sliva postoji zavisnost između oticaja i parametara koji ga izazivaju (intenziteta kiše, infiltracije, topografije, tipa zemljišta...). Površina sliva se predstavlja homogenim elementima u kojima su svi hidrološki parametri uniformni.

Model ima mogućnost proračuna evapotranspiracije pomoću jednačine Ričija (Ritchie) dok se infiltracija obračunava preko modela koji su predložili Green i Ampt.

Površinski oticaj, kao razlika padavina i isparavanja, modelira se numeričkim rešavanjem jednačina kinematskog talasa (izrazi 1 i 2), gde je veza između proticaja i dubine vode data Manning-ovom jednačinom [16] (izraz 3).

Proračun kretanja i transporta sedimenata sa sliva vrši se jednačinom kontinuiteta za ustaljeno kretanje nanosa [9].

Empirijskim relacijama određuje se erozija kišom:

$$
D R=0.027 * C D R * S K D R^{*} A i^{*} R^{2}
$$

gde je $D R$ erozija kišom, $C D R$ faktor kulture i načina obrade iz modela USLE, $S K D R$ erozivnost zemljišta iz modela USLE, $A$ površina i $R$ intenzitet kiše.

Proračun erozije tečenjem vode po terenu se takođe određuje empirijskim izrazom:

$$
D F=0.018 * C D R * S K D R^{*} A i^{*} S L^{*} Q
$$

gde je $S L$ nagib sliva a $Q$ površinski oticaj.

Transportni kapacitet površinskog toka obračunava Yalin-ovom jednačinom (izraz 22).

\subsection{CREAMS}

Model CREAMS (The Chemicals, Runoff, and Erosion from Agricultural Management Systems) razvijen je sa ciljem da omogući procenu uticaja zagađujućih materija sa poljoprivrednih površina na vodotoke [17]. Model je namenjen za modelisanje 
kontinualnih kišnih epizoda ali je, za razliku od modela ANSWERS-2000, predviđen za korišćenje na parcelama manjim od $4 \mathrm{~km}^{2}$.

Evapotransporacija se obračunava pomoću jednačine Ričija. Za obračun infiltracije model koristi SCS metodu ukoliko su padavine zadate kao dnevne, odnosno Green-Ampt metodu ukoliko postoje časovni podaci o padavinama [18]. Tečenje po površini terena se dobija rešavanjem jednačina kinematskog talasa (izrazi 1 i 2 ) uz korišćenje Chezy-jeve veze (izraz 4) između protoka i dubine vode.

Odvajanje sedimenata od osnovne mase tla se računa zasebno za eroziju kišom i eroziju površinskim tečenjem preko empirijskih relacija definisanih u modelu USLE. Transport sedimenata se računa preko jednačine kontinuiteta za ustaljen pronos nanosa. Transportni kapacitet toka obračunava se preko jednačine Yalin-a.

\section{DISKUSIJA I ZAKLJUČCI}

Iz priloženog pregleda nekoliko matematičkih modela oticaja i erozije može se zaključiti da postoje dva pristupa rešavanja problema procene količine erozije sa sliva. Sa jedne strane postoje modeli kontinualnih simulacija kojima se, osim oticaja i erozije tokom jedne kišne epizode, modelišu i događaji između kiša (CREAMS, WEPP, SHETRAN). Sa druge strane postoje i modeli kojima se modeliraju procesi od kišnih epizoda različitog trajanja (KINEROS2, ANSWERS). Svi modeli su predviđeni za procenu oticaja i erozije sa, uglavnom, poljoprivrednih površina veličine $1-2000 \mathrm{~km}^{2}$. Modeli opisuju erozione procese pod uticajem kiše i površinskog oticaja dok modeli CREAMS i WEPP opisuju i eroziju u brazdama. Jedino model CREAMS računa i eroziju u jarugama.

Za opisivanje hidroloških i psamoloških procesa na slivu modeli koriste slične jednačine. Kretanje vode po površini terena se u modelima opisuje empirijskim i jednačinama kinematskog talasa, osim u modelu SHETRAN koji koristi jednačine difuzionog talasa. Kretanje nanosa niz padine sliva i kroz hidrografsku mrežu opisano je jednačinom kontinuiteta za ustaljeno (ANSWERS; CREAMS i WEPP), odnosno neustaljeno kretanje nanosa (KINEROS2, i WEPP). Transportni kapacitet površinskog i oticaja kroz reke modelira se upotrebom jednačina Yalin-a, Engelund-Hansena i Goversa.

Odluka o primeni određenih modela, empirijskih ili matematičkih, zavisi od stepena raspoloživih podataka merenja klimatskih, topografskih, pedoloških, geoloških i vegetacionih uslova na slivu. Iz priloženog pregleda matematičkih modela oticaja i erozije može se zaključiti da rade na vrlo sličnim principima.

\section{LITERATURA}

[1] W. H. Wischmeier and D. D. Smith, "Predicting rainfall erosion losses. Agricultural Handbook 537," 1978.

[2] W. H. Wischmeier and D. D. Smith, “Agriculture Handbook 282," U.S. Department of Agriculture, 1965.

[3] H. Liu, "Bare soil erosion dependence on soil and rainfall properties," University of Houston, Houston, USA, 1999. 
[4] X. C. Zhang, M. A. Nearing, L. D. Norton, W. P. Miller, and L. T. West, "Modeling Interrill Sediment Delivery," Soil Science Society of America Journal, vol. 62, no. 2, p. 438, 1998.

[5] H. Wei, M. A. Nearing, J. J. Stone, D. P. Guertin, K. E. Spaeth, F. B. Pierson, M. H. Nichols, and C. A. Moffet, "A New Splash and Sheet Erosion Equation for Rangelands," Soil Science Society of America Journal, vol. 73, no. 4, p. 1386, 2009.

[6] V. Đukić and S. Petković, "Review of soil erosion and sediment transport models in river basins," Vodoprivreda, vol. 41, no. 4-6, pp. 117-125.

[7] V. Đukić, "Hidrauličko-hidrološki model geneze i transporta nanosa u slivu," Univerzitet uBeogradu, Građevinski fakultet, 2010.

[8] D. J. Semmens, D. C. Goodrich, C. L. Unkrich, R. E. Smith, D. A. Woolhiser, and S. N. Miller, "KINEROS2 and the AGWA modelling Framework," in Hydrological Modelling in Arid and Semi-Arid Areas, Cambridge University Press, 2007.

[9] H. Aksoy and M. L. Kavvas, "A review of hillslope and watershed scale erosion and sediment transport models," CATENA, vol. 64, no. 2-3, pp. 247-271, Dec. 2005.

[10] D. C. Flanagan and M. A. Nearing, "USDA-Water Erosion Prediction Project Hillslope Profile and Watershed Model Documentation," NSERL Report 10.

[11] C. T. Haan, B. J. Barfield, and J. C. Hayes, Design hydrology and sedimentology for small catchments. San Diego, Calif: Academic Press, 1994.

[12] J. C. Bathurst, "Physically-based erosion and sediment yield modelling: the SHETRAN concept," Modelling erosion, sediment transport and sediment yield, $\mathrm{p}$. 47, 2002.

[13] School of Civil Engineering and Geosciences, "SHETRAN Water Flow Component, Equations and Algorithms," Newcastle, Newcastle University, 1995.

[14] B. T. Lukey, J. C. Bathurst, R. A. Hiley, and J. Ewen, "SHETRAN sediment transport component: equations and algorithms," WRSRU/TR/9510/60.0, Oct. 1995.

[15] S. Dabral and M. Cohen, "ANSWERS-2000 Areal Non-point Source Watershed Environment Response Simulation with Questions Graphical User Interface," ABE6254-Simulation of Small Agricultural Watersheds, Project Report 1, Nov. 2011.

[16] D. E. Radcliffe and M. L. Cabrera, Modeling Phosphorus in the Environment. CRC Press, 2006.

[17] W. S. Merritt, R. A. Letcher, and A. J. Jakeman, "A review of erosion and sediment transport models," Environmental Modelling \& Software, vol. 18, no. 8-9, pp. 761799, Oct. 2003.

[18] W. G. Knisel and others, "CREAMS: A field-scale model for chemicals, runoff and erosion from agricultural management systems.," USDA Conservation Research Report, no. 26, 1980.

\section{SHORT REVIEW OF RUNOFF AND EROSION PHYSICALLY BASED MODELS}

Summary: Processes of runoff and erosion are one of the main research subjects in hydrological science. Based on the field and laboratory measurements, and analogous with 
development of computational techniques, runoff and erosion models based on equations which describe the physics of the process are also developed. Several models of runoff and erosion which describes entire process of genesis and sediment transport on the catchment are described and compared.

Keywords: erosion, model, runoff 